\title{
Dry Deposition of Airborne Particles and Characteristics of Polycyclic Aromatic Hydrocarbons in Urban Kaohsiung, Taiwan
}

\author{
H.K. Wang ${ }^{1}$, K.S. Chen ${ }^{1 *}$, J.J. Lu ${ }^{1}$, Y.P. Peng ${ }^{1}$, W.C. Wang ${ }^{1}$, M.Y. Tsai ${ }^{2}$, \\ C.H. Lai ${ }^{3}$ \\ ${ }^{1}$ Institute of Environmental Engineering, National Sun Yat-Sen University, Kaohsiung 80424, \\ Taiwan, ROC. \\ ${ }^{2}$ Environmental Protection Bureau, Kaohsiung County, 83347, Taiwan, ROC \\ ${ }^{3}$ Department of Nursing, Central Taiwan University of Science and Technology, Taichung 40601, \\ Taiwan, ROC.
}

\begin{abstract}
The concentrations of twenty-one individual polycyclic aromatic hydrocarbons (PAHs) and total suspended particles (TSP) were measured using high-volume air samplers at two sites (Tzuo-Yin and Hsiung-Kong) in Kaohsiung City, Taiwan for during four seasons from 2005 to 2006. The gaseous and particulate phases of individual PAHs were identified using a gas chromatograph with a flame-ionization detector (GC/FID). The deposition fluxes of airborne particles at the two sites were measured with dry deposition plates. The results show that the concentrations of total (gas + particulate) PAHs generally followed the seasonal variations of the concentrations of TSP $\left(107.18-117.09 \mu \mathrm{g} / \mathrm{m}^{3}\right)$, being the highest in winter $\left(143.9-182.9 \mathrm{ng} / \mathrm{m}^{3}\right.$ ) and lowest in summer (81.4-95.2 $\left.\mathrm{ng} / \mathrm{m}^{3}\right)$ at both sites. The differences in the results at the two sites are mainly attributed to the different industries at each site. The mean deposition fluxes of airborne particles were between 182.2 and $195.3 \mathrm{mg} / \mathrm{m}^{2}$-day, with a dry deposition velocity of 2.00-2.04 cm/s. Most PAH species were low-weight PAHs (approximately 80.8-82.0\%), followed by high-weight PAHs (10.5-14.6\%) and medium-weight PAHs (6.5-6.8\%). The fractions of gaseous PAHs decreased with molecular weight or ring number. The particle phase (60.2-73.5\%) dominated the high-weight PAHs.
\end{abstract}

Keywords: PAHs; Particulate matter; Dry deposition; Urban air quality.

\footnotetext{
* Corresponding author. Tel.: 886-7-5254406, Fax: 886-7-5254406

E-mail address: shin@mail.nsysu.edu.tw
} 


\section{INTRODUCTION}

The sources of polycyclic aromatic hydrocarbons (PAHs) are primarily incomplete fossil-fuel combustions, such as are emitted from steel-making plants, secondary zinc/aluminum sinter plants, diesel trucks and waste incinerators. Woodburning and wildfires also contribute to the atmospheric levels of PAHs. Ambient levels of PAHs have received considerable attention in recent years (Holsen et al., 1993; Caricchia et al., 1999; Odabasi et al., 1999; Kulkarni and Venkataraman, 2000; Chetwittayachan et al., 2002; Ho et al., 2002; Lee and Lee, 2004), because many PAHs are known to be carcinogenic and mutagenic and are detrimental to human health (IARC, 1987; Menzie, et al., 1992). Although atmospheric PAHs can exist in gaseous and particle phases, they are predominantly associated with particulate matter (PM). This suggests that particulate PAHs are regarded as significant hazardous substances to human health through breathing.

Kaohsiung ( $22^{\circ} 38^{\prime} \mathrm{N}, 120^{\circ} 17^{\prime} \mathrm{E}$ ), located in southern Taiwan, is an industrialized and densely populated harbor city, with approximately 1.49 million inhabitants, 1,281,000 registered vehicles (380,000 cars, 886,000 motorcycles, and 15,000 trucks) and an area of $153.6 \mathrm{~km}^{2}$. Dense traffic and industrial activities have made Kaohsiung City and surrounding Kaohsiung and Pingtung counties the region with the poorest air quality in Taiwan. The air in southern Taiwan is of the poorest quality between the late fall, winter and middle spring, either due to increased ground-level concentrations of PM or ozone associated with unfavorable meteorological conditions (Chen et al., 2004). Although some work has been done on the understanding of vehicular traffic emissions of PAHs (Lee et al., 1995), as well as the size and dry deposition of road dust PAHs in Kaohsiung City (Yang et al., 1999), emissions of PAHs from medical incinerators (Lee et al., 2002), and dry deposition of PAHs in central Taiwan (Fang et al., 2004), little information is available on the atmospheric levels of PAHs in southern Taiwan, particularly those associated with the phase distribution of atmospheric PAHs and their seasonal variations.

Twenty-one PAH species, from two to seven rings, at the two monitor sites associated with different industry, were conducted in Kaohsing city in 2005 and 2006. The objectives of this work were to quantify: (1) the atmospheric concentrations of PAH species and their seasonal variations at two monitoring sites with different types of industry; (2) the fractions of gaseous and particulate phases of PAHs, and: (3) dry deposition flux of airborne particles. The results should be helpful for understanding $\mathrm{PAH}$ impact on the environment and for helping to develop a database for estimating their source contributors and assessing the health risk to neighboring communities. 


\section{EXPERIMENTAL PROCEDURES}

\section{Sampling sites and periods}

The sampling sites were located in Tzuo-Yin and Hsiung-Kong in the northern and central parts of Kaohsiung City, respectively (Fig. 1). Taiwan's EPA (Environmental Protection Administration) has set up air-quality monitoring stations at the two sites where hourly air quality and meteorological data, including $\mathrm{PM}_{10}$, temperature and winds, are available. As indicated in Fig. 1, the Kaohsiung area includes six large industrial complexes, two in Kaohsiung City and four in Kaohsiung County. The distance between the Tzuo-Yin and Hsiung-Kong sites is approximately $17 \mathrm{~km}$.

Samples were obtained over 14 days at both sites, including two summer days in 2005, four days in the fall of 2005, winter of 2005, and spring of 2006. Table 1 presents the meteorological conditions at the sampling sites, including temperature, wind speed, period of sunshine and relative humidity.

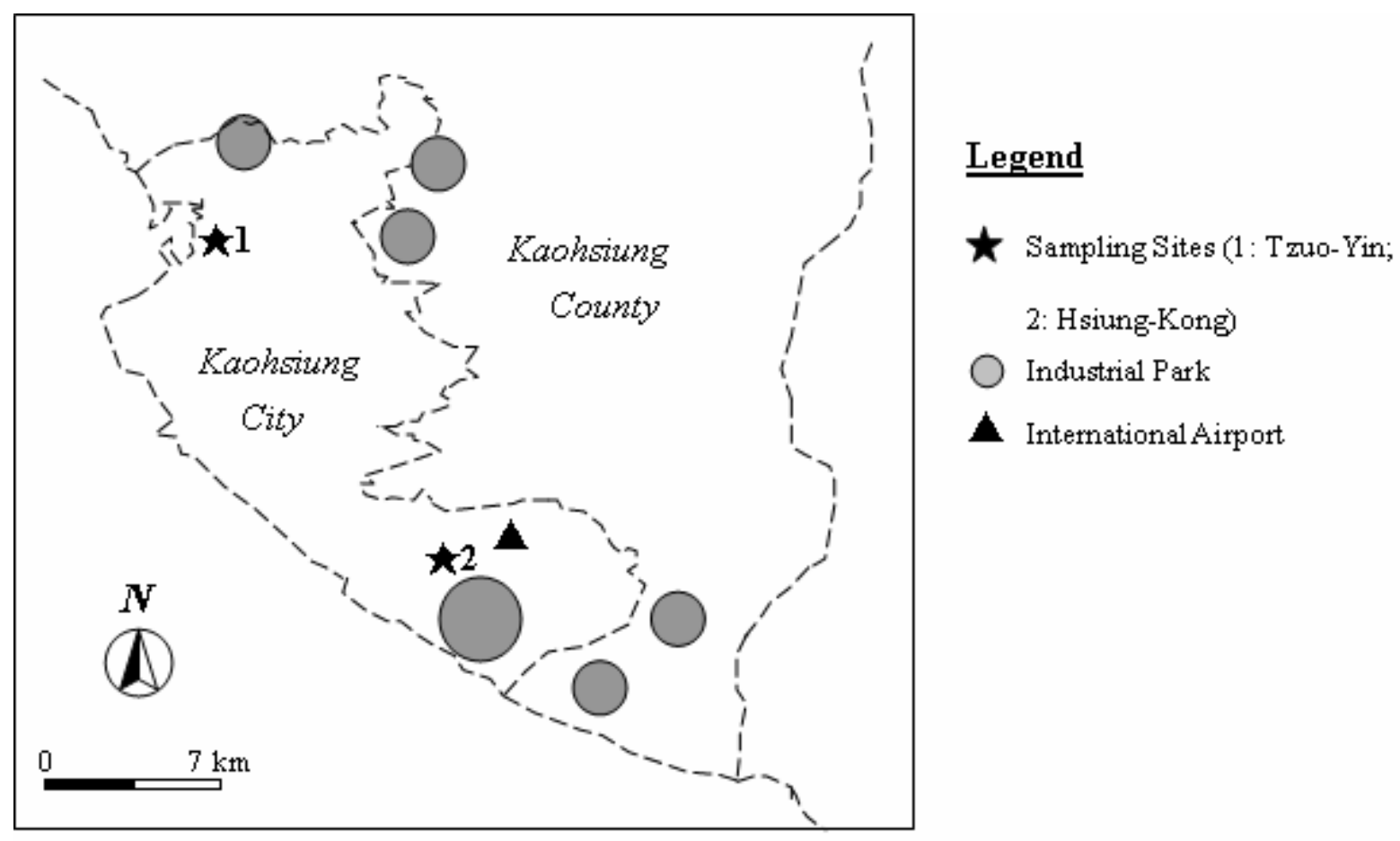

Fig. 1. Locations of the two sampling sites in Kaohsiung City. 
Table 1. Meteorological conditions at the two sites in Kaohsiung City in 2005 and 2006.

\begin{tabular}{|c|c|c|c|c|c|}
\hline Date & $\begin{array}{c}\text { Temperature } \\
\left({ }^{\circ} \mathrm{C}\right) \\
\end{array}$ & $\begin{array}{c}\text { Wind speed } \\
(\mathrm{m} / \mathrm{s})\end{array}$ & Wind direction & $\begin{array}{c}\text { Period of } \\
\text { Sunshine (h) }\end{array}$ & $\begin{array}{c}\text { Relative humidity } \\
(\%)\end{array}$ \\
\hline \multicolumn{6}{|c|}{ (a) Tzuo-Yin site } \\
\hline 2005/07/05 & 31.0 & 2.00 & WSW & 12.3 & 74 \\
\hline 2005/07/15 & 30.3 & 2.15 & NW & 9.7 & 75 \\
\hline 2005/09/28 & 27.9 & 1.57 & $\mathrm{~W}$ & 7.8 & 76 \\
\hline 2005/09/29 & 28.2 & 1.63 & W & 10.0 & 76 \\
\hline 2005/09/30 & 28.0 & 1.69 & WSW & 8.8 & 77 \\
\hline 2005/10/01 & 28.5 & 2.49 & ENE & 8.4 & 75 \\
\hline 2005/12/09 & 19.9 & 1.91 & NW & 8.0 & 72 \\
\hline $2005 / 12 / 10$ & 21.1 & 2.11 & NW & 6.4 & 73 \\
\hline 2005/12/11 & 21.3 & 3.43 & NW & 2.7 & 69 \\
\hline $2005 / 12 / 12$ & 17.3 & 3.52 & NW & 0.0 & 70 \\
\hline 2006/03/06 & 22.2 & 1.79 & NW & 11.1 & 63 \\
\hline 2006/03/07 & 22.5 & 2.04 & NW & 10.8 & 69 \\
\hline 2006/03/08 & 22.1 & 2.4 & NW & 5.7 & 74 \\
\hline 2006/03/09 & 23.1 & 2.85 & NW & 6.6 & 69 \\
\hline \multicolumn{6}{|c|}{ (b) Hsiung-Kong site } \\
\hline 2005/07/09 & 30.9 & 2.36 & NNE & 11.6 & 77 \\
\hline 2005/07/18 & 27.4 & 2.32 & $\mathrm{~W}$ & 0.0 & 94 \\
\hline 2005/10/02 & 30.5 & 2.88 & SW & 0.4 & 86 \\
\hline 2005/10/03 & 30.0 & 1.47 & $\mathrm{~S}$ & 11.3 & 77 \\
\hline $2005 / 10 / 04$ & 30.1 & 1.86 & ENE & 5.9 & 79 \\
\hline 2005/10/05 & 30.5 & 2.09 & $\mathrm{~W}$ & 9.2 & 79 \\
\hline 2005/12/05 & 19.7 & 1.55 & ENE & 0.0 & 59 \\
\hline 2005/12/06 & 18.3 & 1.27 & ENE/W & 1.2 & 58 \\
\hline 2005/12/07 & 20.0 & 1.12 & NNE & 0.0 & 66 \\
\hline 2005/12/08 & 21.3 & 1.38 & NNE & 1.6 & 67 \\
\hline 2006/03/02 & 22.2 & 1.07 & $\mathrm{~N}$ & 5.4 & 70 \\
\hline 2006/03/03 & 22.5 & 1.12 & $\mathrm{~N}$ & 0.0 & 64 \\
\hline 2006/03/04 & 22.1 & 1.37 & $\mathrm{~N}$ & 0.0 & 66 \\
\hline 2006/03/05 & 23.1 & 1.53 & NNE & 9.5 & 67 \\
\hline
\end{tabular}




\section{Sampling of airborne particulate matter and PAHs}

Air samples for the particulate and gas phases of PAHs were collected for $24 \mathrm{~h}$ using a PS-1 sampler (GPS1 PUF sampler, General Metal Work), operated at an airflow rate of $115 \mathrm{~L} / \mathrm{min}$. In the PS-1 sampler, a 102-mm-diamter quartz filter with a pore size of $0.8 \mu \mathrm{m}$ was used to collect the total suspended particles (TSP) and particulate PAHs. Before sampling, the filters were heated in an oven at $450^{\circ} \mathrm{C}$ for $8 \mathrm{~h}$ to remove volatile substances, and then put in an isothermal box for cooling and weighing. An electrical balance sensitive to $0.01 \mathrm{mg}$ was used to measure the weight.

A glass cartridge containing a 30-mm polyurethane form (PUF) plug, followed by a 40-mm XAD-16 resin, and finally a 30-mm PUF plug, cleaned by sequential extraction, was used to collect the gas-phase PAHs. Breakthrough tests indicated no PAHs being detected at the third stage of the XAD-16 resin.

\section{PAH analysis}

The particulate PAHs in the sampler were extracted in a Soxhelt extractor with a solvent solution of $250 \mathrm{~mL}$ (a mixture of $125 \mathrm{~mL}$-hexdane and $125 \mathrm{~mL}$ dichloromethane) for $24 \mathrm{~h}$. The extract was then concentrated, cleaned and re-concentrated with ultra-pure nitrogen to exactly 0.5 $\mathrm{mL}$. Twenty-one PAH species, either in the particulate or gaseous phase, were analyzed using a gas chromatograph with a flame-ionization detector (GC/FID, Shimadzu GC-14A) with a GC capillary column of $30 \mathrm{~m} \times 0.25 \mathrm{~mm} \times 0.25 \mu \mathrm{m}$ (Suplco Equaity-5). The oven temperature was programmed to be from $50^{\circ} \mathrm{C}$ to $100^{\circ} \mathrm{C}$ at a rate of $20^{\circ} \mathrm{C} / \mathrm{min}$, then from $100^{\circ} \mathrm{C}$ to $290^{\circ} \mathrm{C}$ at a rate of $3^{\circ} \mathrm{C} / \mathrm{min}$, and held at $290^{\circ} \mathrm{C}$ for $40 \mathrm{~min}$; the injection temperature was set at $310^{\circ} \mathrm{C}$ with nitrogen as the carrier gas.

Prior to analysis, calibration curves for the 21 PAHs were obtained by spiking seven known quantities of substances, all with an $R^{2}$ of the calibration curve above 0.995 . The detection limit (DL) was three times the standard deviation from seven tests for each species. The full and abbreviated names of the 21 PAHs are listed in Table 2, together with the accuracy and DLs. Herein, PAHs are categorized into LW-PAHs (2-3 rings), MW-PAHs (4 rings) and HW-PAHs (5-7 rings). Both field and laboratory blank samples were prepared and analyzed; all data were corrected with reference to a blank. Recovery efficiencies of 83-98\% were achieved. 
Table 2. Accuracy and detection limit (DL) of 21 PAHs.

\begin{tabular}{|c|c|c|c|c|}
\hline & Full name & Abbreviated & $\begin{array}{c}\text { Accuracy } \\
(\%)\end{array}$ & $\begin{array}{l}\text { DL } \\
\text { (ng) }\end{array}$ \\
\hline \multirow{6}{*}{ LW-PAHs } & Acenaphthene & Aср & $91.5 \pm 6.24$ & 0.189 \\
\hline & Acenaphthyene & Асру & $77.9 \pm 14.35$ & 0.184 \\
\hline & Anthracene & Ant & $92.2 \pm 4.34$ & 0.143 \\
\hline & Fluorene & Flu & $90.2 \pm 10.03$ & 0.172 \\
\hline & Naphthalene & $\mathrm{NaP}$ & $83.2 \pm 10.0$ & 0.283 \\
\hline & Phenanthrene & PA & $95.9 \pm 6.24$ & 0.144 \\
\hline \multirow{4}{*}{ MW-PAHs } & Benz[a]anthracene & $\mathrm{BaA}$ & $91.5 \pm 5.55$ & 0.137 \\
\hline & Chrysene & CHR & $88.2 \pm 5.11$ & 0.125 \\
\hline & Fluoranthene & FL & $89.5 \pm 16.25$ & 0.112 \\
\hline & Pyrene & Pyr & $88.2 \pm 11.12$ & 0.082 \\
\hline \multirow{11}{*}{ HW-PAHs } & Benz[a]pyrene & $\mathrm{BaP}$ & $87.3 \pm 4.27$ & 0.115 \\
\hline & Benz[b]fluoranthene & $\mathrm{BbF}$ & $88.9 \pm 7.53$ & 0.102 \\
\hline & Benz[e]pyrene & $\mathrm{BeP}$ & $95.5 \pm 1.62$ & 0.114 \\
\hline & Benz[ghi]perylene & BghiP & $96.2 \pm 1.18$ & 0.113 \\
\hline & Benz[k]fluoranthene & $\mathrm{BkF}$ & $92.7 \pm 5.37$ & 0.123 \\
\hline & Benzo[b]chrycene & $\mathrm{BbC}$ & $87.3 \pm 5.13$ & 0.12 \\
\hline & Coronene & COR & $97.0 \pm 2.45$ & 0.104 \\
\hline & Cyclopenta[c,d]pyrene & CYC & $87.8 \pm 11.83$ & 0.115 \\
\hline & Dibenz[a,h]anthracene & DBA & $95.3 \pm 1.83$ & 0.085 \\
\hline & Indeno[1,2,3-cd]pyrene & IND & $89.4 \pm 5.27$ & 0.103 \\
\hline & Perylene & PER & $88.3 \pm 5.31$ & 0.162 \\
\hline
\end{tabular}

\section{Dry deposition plate}

Dry-deposition fluxes of airborne particles were measured using three identical smooth surface plates, attached to three arms of a horizontal template on a stainless-steel stand; the horizontal distance between neighboring plates was $50 \mathrm{~cm}$. Each plate was made of polyvinyl chloride (PVC) and was $21.6 \mathrm{~cm}$ long, $8.0 \mathrm{~cm}$ wide and $0.8 \mathrm{~cm}$ thick, with a sharp leading edge $(<10$-degree angle). The plate was cut out so that it would slide onto a 3-cm diameter rod. Two screws were used to fasten the plate to a wind van, allowing the plate to swing freely into the wind direction. This type of the deposition plate has been extensively used as a surrogate to measure deposited substances (Holsen et al., 1993; Lee et al., 1995; Yang et al., 2005). 
A quartz filter $(10 \mathrm{~cm} \times 8 \mathrm{~cm})$ was glued on each plate to collect impacted particles for $48 \mathrm{~h}$. After the grease was sprayed onto the filters (each with $44 \mathrm{~cm}^{2}$ of exposed surface), the filters were baked in an oven at $60^{\circ} \mathrm{C}$ for 90 min to remove volatile substances. The filters were weighed before and after sampling to determine the total mass of the particles collected. The mean concentration of airborne particles was obtained by averaging the particle weights of the three quartz filters.

\section{RESULTS AND DISCUSSION}

\section{Seasonal variations of TSP and total PAHs}

Fig. 2 displays the seasonal mean concentrations of TSP and total (particulate + gas) PAHs at the Tzuo-Yin and Hsiung-Kong sites. It reveals that the concentrations of TSP were highest in winter (124.33 and $149.02 \mu \mathrm{g} / \mathrm{m}^{3}$ ), followed by spring (122.80 and $130.59 \mu \mathrm{g} / \mathrm{m}^{3}$ ), fall (98.72 and $110.94 \mu \mathrm{g} / \mathrm{m}^{3}$ ) and summer (52.52 and $58.61 \mu \mathrm{g} / \mathrm{m}^{3}$ ) at both Tzuo-Yin and Hsiung-Kong. This is consistent with earlier studies showing that southern Taiwan usually has the worst air quality during fall, winter or early spring, and has the best quality in summer (Chen et al., 2004). The prevailing winds in fall, winter or spring over southern Taiwan are mostly from the northeast (NE) to east (E), originating from mainland China and accompanying relatively cold, dry and light winds, unfavorable for pollutant dispersion. While the prevailing winds in the summer over southern Taiwan are mostly southerly (S) to southwesterly (SW), originating from southern Pacific Ocean and accompanying clouds, rains, tropical depressions or typhoons, favorable for pollutant dispersion (Chen et al., 2004).

The concentrations of total PAHs generally followed the seasonal variations of TSP, being the highest in winter (143.9-182.9 $\mathrm{ng} / \mathrm{m}^{3}$ ) and lowest in summer (81.4-95.2 $\mathrm{ng} / \mathrm{m}^{3}$ ) at both sites; the second and third highest at Tzuo-Yin were in spring $\left(130.6 \mathrm{ng} / \mathrm{m}^{3}\right)$ and fall $\left(110.9 \mathrm{ng} / \mathrm{m}^{3}\right)$, and fall $\left(129.7 \mathrm{ng} / \mathrm{m}^{3}\right)$ and spring $\left(121.8 \mathrm{ng} / \mathrm{m}^{3}\right)$ at Hsiung-Kong. Comparisons of overall mean concentrations of PAHs with other studies are given below. 

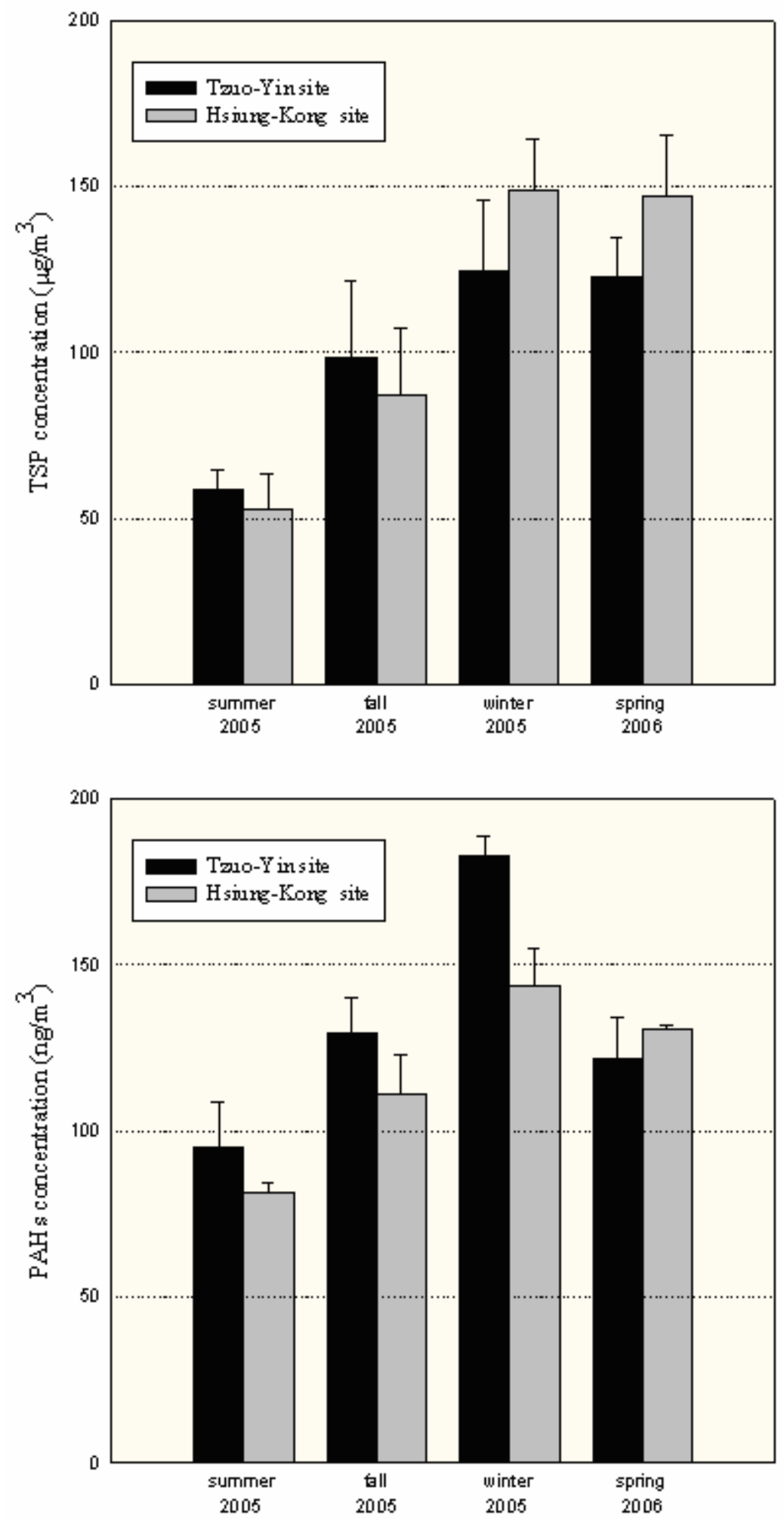

Fig. 2. Mean seasonal concentrations of TSP and total PAHs at the Tzuo-Yin and Hsiung-Kong sites in Kaohsiung City in 2005 and 2006. 


\section{General characteristics of PAHs}

Table 3 summarizes the ranges and the mean concentrations of 21 (gas + particulate) PAH species averaged over all data. It is evident that most PAHs were LW-PAHs (80.8\% at Tzuo-Yin and $82.0 \%$ at Hsiung-Kong), followed by HW-PAHs (12.7\% and 11.2\%) and MW-PAHs (6.5\% and 6.8\%). In particular, NAP, an LW-PAH, is the most abundant species at the two sites: $74.30 \pm$ $15.72 \mathrm{ng} / \mathrm{m}^{3}$ at Tzuo-Yin and $94.74 \pm 24.13 \mathrm{ng} / \mathrm{m}^{3}$ at Hsiung-Kong, representing about $63.0 \%$ and $70.2 \%$ of total PAHs, respectively. The remaining 20 species were in the ranges of $0.83-5.64$ $\mathrm{ng} / \mathrm{m}^{3}$ at Tzuo-Yin and $0.77-4.86 \mathrm{ng} / \mathrm{m}^{3}$ at Hsiung-Kong.

Notably, the overall mean concentrations of total PAHs (and TSP) at Tzuo-Yin were approximately $118.01 \mathrm{ng} / \mathrm{m}^{3}\left(107.18 \mu \mathrm{g} / \mathrm{m}^{3}\right)$, and $134.98 \mathrm{ng} / \mathrm{m}^{3}\left(117.09 \mu \mathrm{g} / \mathrm{m}^{3}\right)$ at Hsiung-Kong, which is approximately $14.4 \%$ (9.25\%) lower at Tzuo-Yin than Hsiung-Kong. This is consistent with the fact that the primary industry in the northern part (as in Tzuo-Yin) of Kaohsiung City is an oil refinery, and plastic and chemical plants, where the emissions of volatile organic compounds are dominant. Those in the southern part (as in Hsiung-Kong) of Kaohsiung City are steel-making plants (either using iron ores or electric-arc ovens) and secondary zinc/aluminum sinter plants, where the emissions of particulate matter are dominant. Comparisons with other studies revealed that the present results were somewhat lower than $198-298 \mathrm{ng} / \mathrm{m}^{3}$ at a road intersection (Yang, 1998) and commensurate with about $115 \mathrm{ng} / \mathrm{m}^{3}$ at a university campus (Liu, 2006), both in Kaohsiung City. But the present results were much lower than those in Taichung (Fang et al., 2004), showing $1650 \pm 1427,1220 \pm 520$ and $831 \pm 427 \mathrm{ng} / \mathrm{m}^{3}$ at industry, urban and rural sites, respectively. 
Table 3. Concentrations (mean \pm SD) of 21 total (gas + particulate) PAH species at the Tzuo-Yin and Hsiung-Kong sites in Kaohsiung City.

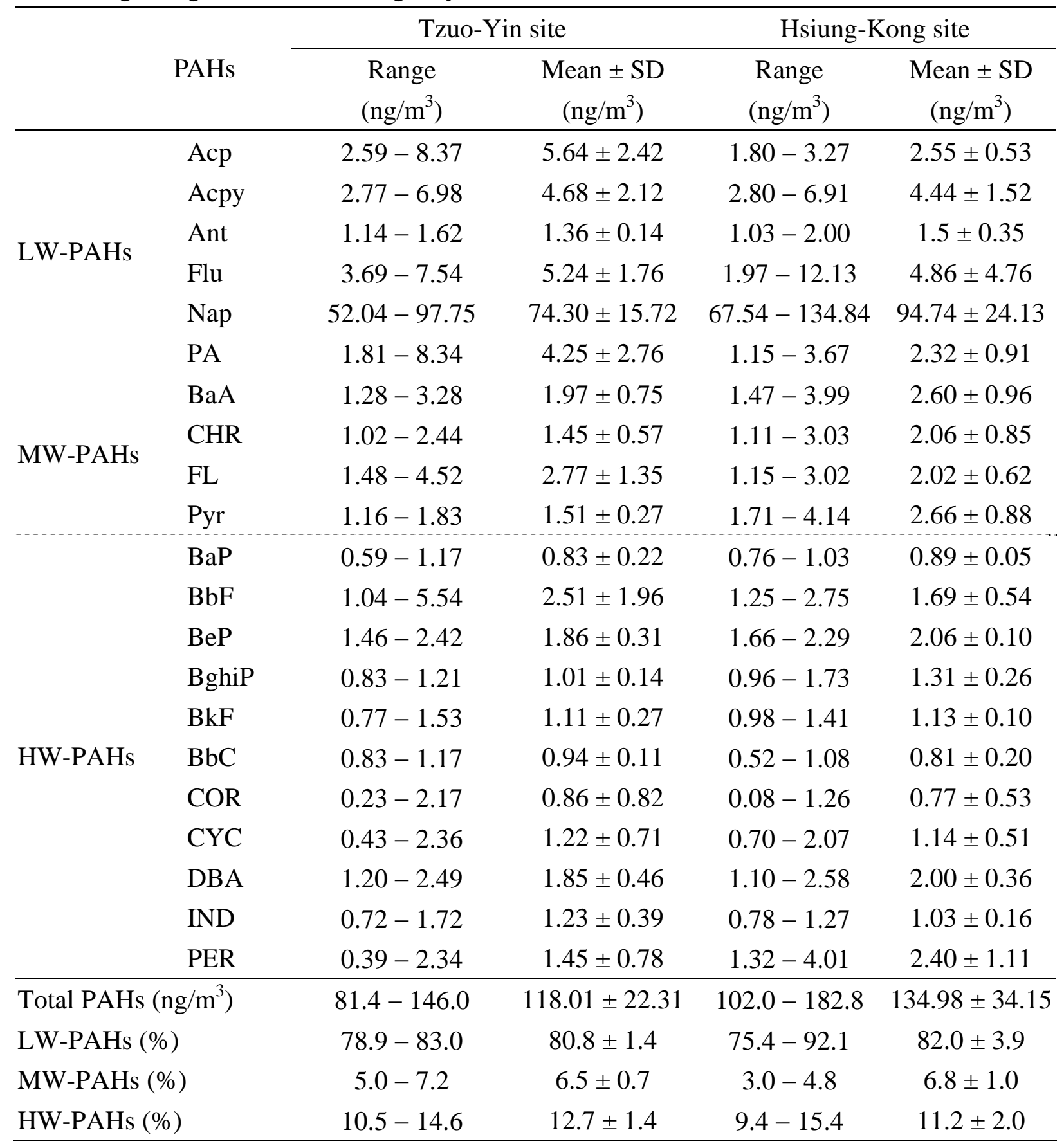

\section{Phase distribution in PAHs}

Atmospheric PAHs are partitioned between the gas phase and particulate matter, depending on their molecular weights or ring numbers. Table 4 summarizes the overall mean fractions of gaseous and particulate PAH species at both sites. It reveals that LW-PAHs mostly existed in a gaseous form, ranging from 55.9\% (66.9\%) to 95.9\% (96.6\%) at Tzuo-Yin (and Hsiung-Kong); 
of note, over 95\% of Nap existed in gaseous phase. On average, about $91.1 \%$ of the LW-PAHs were in gaseous form, and the remaining $8.9 \%$ were in particulate form, agreeing well with the findings (90.3\% in gas phase and $9.7 \%$ in particle phase) at an urban site in Taichung (Fang et al., 2005). About 54.8\% (70.3\%) of the MW-PAHs were in gaseous form at Tzuo-Yin (Hsiung-Kong), and about $45.2 \%$ (29.7\%) were in particulate form, differing from those (96.5.\% in gas phase and 3.5\% in particle phase) at an urban site in Taichung (Fang et al., 2005).

Table 4. Phase distribution (\%) of 21 PAHs at the Tzuo-Yin and Hsiung-Kong sites in Kaohsiung City.

\begin{tabular}{|c|c|c|c|c|c|}
\hline & \multirow{2}{*}{ PAHs } & \multicolumn{2}{|c|}{ Tzuo-Yin site } & \multicolumn{2}{|c|}{ Hsiung-Kong site } \\
\hline & & Gaseous (\%) & Particulate (\%) & Gaseous (\%) & Particulate (\%) \\
\hline \multirow{6}{*}{ LW-PAHs } & Aсp & 65.9 & 34.1 & 74.2 & 25.8 \\
\hline & Асру & 82.4 & 17.6 & 66.9 & 33.1 \\
\hline & Ant & 55.9 & 44.1 & 67.1 & 32.9 \\
\hline & Flu & 83.2 & 16.8 & 76.6 & 23.4 \\
\hline & Nap & 95.9 & 4.1 & 96.6 & 3.4 \\
\hline & PA & 75.2 & 24.8 & 75.6 & 24.4 \\
\hline \multirow{4}{*}{ MW-PAHs } & $\mathrm{BaA}$ & 49.4 & 50.6 & 58.7 & 41.3 \\
\hline & CHR & 46.4 & 53.6 & 62.5 & 37.5 \\
\hline & FL & 62.4 & 37.6 & 75.7 & 24.3 \\
\hline & Pyr & 57.3 & 42.7 & 82.4 & 17.6 \\
\hline \multirow{11}{*}{ HW-PAHs } & $\mathrm{BaP}$ & 34.8 & 65.2 & 39.4 & 60.6 \\
\hline & $\mathrm{BbF}$ & 25.8 & 74.2 & 33.9 & 66.1 \\
\hline & $\mathrm{BeP}$ & 19.8 & 80.2 & 30.0 & 70.0 \\
\hline & BghiP & 23.9 & 76.1 & 32.9 & 67.1 \\
\hline & $\mathrm{BkF}$ & 23.2 & 76.8 & 41.0 & 59.0 \\
\hline & $\mathrm{BbC}$ & 22.4 & 77.6 & 51.1 & 48.9 \\
\hline & COR & 16.5 & 83.5 & 22.7 & 77.3 \\
\hline & CYC & 27.5 & 72.5 & 48.1 & 51.9 \\
\hline & DBA & 28.4 & 71.6 & 53.1 & 46.9 \\
\hline & IND & 44.8 & 55.2 & 32.1 & 67.9 \\
\hline & PER & 38.1 & 61.9 & 49.8 & 50.2 \\
\hline \multicolumn{2}{|c|}{ total PAHs (\%) } & 53.4 & 46.6 & 44.3 & 55.7 \\
\hline \multicolumn{2}{|c|}{ LW-PAHs (\%) } & 91.1 & 8.9 & 93.1 & 6.9 \\
\hline \multicolumn{2}{|c|}{ MW-PAHs (\%) } & 54.8 & 45.2 & 70.3 & 29.7 \\
\hline \multicolumn{2}{|c|}{ HW-PAHs (\%) } & 26.5 & 73.5 & 39.8 & 60.2 \\
\hline
\end{tabular}


The fractions of gaseous PAHs were decreased significantly in HW-PAHs. On average, about 73.5\% (60.2\%) of HW-PAHs were in a particulate form, and only about $26.5 \%$ (39.8\%) of HW-PAHs were in a gaseous form at Tzuo-Yin (Hsiung-Kong), agreeing with the findings (34.0\% in gas phase and 66.0\% in particle phase) at an urban site in Taichung (Fang et al., 2005). Generally, the present results are consistent with the fact that a large atmospheric fraction of the three-ring PAHs is in the gaseous form; gaseous and particulate phases are important in the four-ring PAHs, and the particulate phase dominates for five- or more-ring PAHs (Yamasaki et al., 1982).

\section{Dry deposition flux of airborne particles}

Table 5 shows the deposition fluxes of airborne particles ranging from $110.2-290.5 \mathrm{mg} / \mathrm{m}^{2}$-day (with a mean of $195.3 \mathrm{mg} / \mathrm{m}^{2}$-day) at the Tzuo-Yin site and $51.8-280.2 \mathrm{mg} / \mathrm{m}^{2}$-day (with a mean of $182.5 \mathrm{mg} / \mathrm{m}^{2}$-day) at the Hsiung-Kong site. Many factors, including traffic and industrial activity, wind speeds, relative humidity, the season and surface roughness affect the dry deposition fluxes of particles. Although the mean deposition flux of particles at Tzuo-Yin was slightly higher (about 7\%) than that at Hsiung-Kong, the presented results are in the range of the reported results. For instance, the dry deposition flux of airborne particles is $163-193 \mathrm{mg} / \mathrm{m}^{2}$-day in Chicago (Holsen et al., 1993; Li and Kamens, 1993), 97-360 mg/m²-day in Seoul and 120-180 $\mathrm{mg} / \mathrm{m}^{2}$-day in Inchon in Korea (Bae et al., 2002), 26-43 mg/ $\mathrm{m}^{2}$-day in Tsukuba in Japan (Shannigrahi et al., 2005), and 110-190 mg/m²-day in urban and rural sites of western Greece (Terzi and Samara, 2005).

Table 5. Total dry deposition mass at the Tzuo-Yin and Hsiung-Kong sites in Kaohsiung City.

\begin{tabular}{lcc}
\hline Site & Range $\left(\mathrm{mg} / \mathrm{m}^{2}\right.$-day) & Mean $\left(\mathrm{mg} / \mathrm{m}^{2}\right.$-day) \\
\hline Chicago $^{a}$ & $163-193$ & - \\
Seoul (Korea) $^{b}$ & $97-360$ & 265.7 \\
Inchon (Korea) $^{b}$ & $120-180$ & 150.0 \\
Tusukuba (Japan) $^{c}$ & $26-43$ & 35.9 \\
Western Greece $^{d}$ & $110-190$ & - \\
Tzuo-Yin $^{e}$ & $110.2-290.5$ & 195.3 \\
Hsiung-Kong $^{e}$ & $51.8-280.2$ & 182.5 \\
\hline
\end{tabular}

Note: ${ }^{a}$ Holsen et al. (1993) and Li and Kamens (1993); ${ }^{b}$ Bae et al. (2002); ${ }^{c}$ Shannigrahi et al. (2005); ${ }^{d}$ Terzi and Samara (2005); ${ }^{e}$ This study.

The mean dry deposition velocity, $V_{d}$, of airborne particles can be estimated by dividing the deposition flux by the overall mean concentration of TSP, neglecting the minor contribution from gaseous species. The calculated $V_{d}$ was nearly equal at the two sites: $2.04 \mathrm{~cm} / \mathrm{s}$ at Tzuo-Yin and 
$2.00 \mathrm{~cm} / \mathrm{s}$ at Hsiung-Kong. These findings are commensurate with $1.2-2.5 \mathrm{~cm} / \mathrm{s}$ in central Taiwan (Yang et al., 2005) and 0.5-2 cm/s of total PAHs in the Lake Michigan area of the USA (Franz et al., 1998). Note that we did not analyze the concentrations of PAHs from the samples of dry deposition experiments, and therefore could not employ the model to estimate the dry deposition flux and dry deposition velocity of PAHs.

\section{CONCLUSIONS}

The concentrations of total PAHs generally followed the pattern of seasonal variations of TSP (107.18 and $117.09 \mu \mathrm{g} / \mathrm{m}^{3}$ ), being the highest in winter (143.9 and $182.9 \mathrm{ng} / \mathrm{m}^{3}$ ) and the lowest in summer (81.4 and $95.2 \mathrm{ng} / \mathrm{m}^{3}$ ) at the Tzuo-Yin and Hsiung-Kong sites in Taiwan. The differences in the results at the two sites are mainly attributed to the different industries at each site. Emissions of volatile organic compounds from stationary sources are important at Tzuo-Yin, while emissions of particulate matter from stationary sources are important at the Hsiung-Kong site. The mean deposition fluxes of airborne particles were between 182.2 and $195.3 \mathrm{mg} / \mathrm{m}^{2}$-day, with a dry deposition velocity of $2.00-2.04 \mathrm{~cm} / \mathrm{s}$.

Most PAH species were LW-PAHs (about 80.8-82.0\%), followed by HW-PAHs (10.5-14.6\%) and MW-PAHs (6.5-6.8\%). Furthermore, the LW-PAHs mostly existed in a gaseous form, ranging from 55.9 to $95.9 \%$ at Tzuo-Yin and 66.9 to $96.6 \%$ at Hsiung-Kong; notably, over 95\% of Nap existed in gaseous phase. The fractions of gaseous PAHs were found to decrease with molecular weight or ring number. On average, approximately 54.8-70.3\% of MW-PAHs were in gaseous form, and 29.7-45.2\% of MW-PAHs were in particulate form. The particulate phase dominated the HW-PAHs at both sites, being $60.2-73.5 \%$, while only $26.5-39.8 \%$ were in a gaseous form.

\section{ACKNOWLEDGEMENT}

The National Science Council in Taiwan supported this work under grant NSC-94-2211-E-110-010.

\section{REFERENCES}

Bae, S.Y., Yi, S.M. and Kim, Y.P. (2002). Temporal and Spatial Variations of the Particle Size Distribution of PAHs and their Dry Deposition Fluxes in Korea. Atmos. Environ. 36: 5491-5500.

Caricchia, A.M., Chiavarini, S. and Pezza, M. (1999). Polycyclic Aromatic Hydrocarbons in the Urban Atmospheric Particulate Matter in the City of Naples (Italy). Atmos. Environ. 33: 
3731-3738.

Chen, K.S., Ho, Y.T., Lai, H.C., Tsai, Y.A. and Chen, S.J. (2004). Trends in Concentration of Ground-level Ozone and Meteorological Conditions During High Ozone Episodes in Kao-Ping Airshed, Taiwan. Air and Waste Manage. Assoc. 54: 36-48.

Chetwittayachan, T., Shimazaki, D. and Yamamoto, K. (2002). A Comparison of Temporal Variation of Particle-bound Polycyclic Aromatic Hydrocarbons (PAHs) Concentration in Different Urban Environments: Tokyo, Japan, and Bangkok, Thailand. Atmos. Environ. 36: 2027-2037.

Fang, G.C., Chang, K.F., Lu, C. and Bai, H. (2004). Estimations of PAHs Dry Deposition and BaP Toxic Equivalence Factors (TEFs) Study at Urban, Industrial Park and Rural Sampling Sites in Central Taiwan, Taichung. Chemosphere 55: 787-796.

Franz, T.P., Eisenreich, S.J., and Holsen, T.M. (1998), Dry Deposition of Particulate Polychlorinated Biphenyls and Polycyclic Aromatic Hydrocarbons to Lake Michigan. Environ. Sci. Technol. 32: 3681-3688.

Ho, K.F., Lee, S.C., Chiu, G.M.Y. (2002). Characterization of Selected Volatile Organic Compounds, Polycyclic Aromatic Hydrocarbons and Carbonyl Compounds at a Roadside Monitoring Station. Atmos. Environ. 36: 57-65.

Holsen, T.M., Noll, K.E., Fang, G.C., Lee, W.J. and Lin, J.M. (1993). Dry Deposition and Particle Size Distributions Measured during the Lake Michigan Urban Air Toxics Study. Environ. Sci. Technol. 27: 1327-1333.

IARC (1987). IARC Monographs on the Evaluation of the Carcinogenic Risk of Chemicals to Humans, Suppl. 7. International Agency for Research on Cancer (IARC), Lyons, France.

Kulkarni, P. and Venkataraman, C. (2000). Atmospheric Polycyclic Aromatic Hydrocarbons in Mumbai, India. Atmos. Environ. 34: 2785-2790.

Lee, B.K. and Lee, C.B. (2004). Development of an Improved Dry and Wet Deposition Collector and the Atmospheric Deposition of PAHs onto Ulsan Bay, Korea. Atmos. Environ. 38: 863-871.

Lee, W.J., Wang, Y.F., Lin, T.C., Chen, Y.Y., Lin, W.C., Ku, C.C. and Cheng, J.T. (1995). PAH Characteristics in the Ambient Air of Traffic Source. Sci. Total Environ. 1559: 185-200.

Lee, W.J., Liow, M.C., Tsai, P.J. and Hsieh, L.T. (2002). Emissions of Polycyclic Aromatic Hydrocarbons from Medical Waste Incinerators. Atmos. Environ. 36: 781-790.

Li, C.K. and Kamens, R.M. (1993). The Use of Polycyclic Aromatic Hydrocarbons as Source Signatures in Receptors Modeling. Atmos. Environ. 27: 523-532.

Liu, C.H. (2006). The Influence of Aerosol Size on Gas/Particle Partitioning Coefficient of Polycyclic Aromatic Hydrocarbons (PAHs) in the Atmosphere. MS thesis, Department of Safety, Health and Environmental Engineering, National Kaohsiung First University of Science and Technology, Kaohsiung, Taiwan. 
Menzie, C.A., Potocki, B.B. and Santodonato, J. (1992). Exposure to Carcinogenic PAHs in the Environment. Environ. Sci. Technol. 26: 1278-1284.

Odabasi, M., Vardar, N., Sofuoglu, A., Tasdemir, Y. and Holsen, T.M. (1999). Polycyclic Aromatic Hydrocarbons (PAHs) in Chicago air. Sci. Total Environ. 227: 57-67.

Shannigrahi, A.S., Fukushima, T. and Ozaki, N. (2005). Comparison of Different Methods for Measuring Dry Deposition Fluxes of Particulate Matter and Polycyclic Aromatic Hydrocarbons (PAHs) in the Ambient Air. Atmos. Environ. 39: 653-662.

Terzi, E. and Samara, C. (2005). Dry Deposition of Polycyclic Aromatic Hydrocarbons in Urban and Rural Sites of Western Greece. Atmos. Environ. 39: 6261 - 6270.

Yamasaki, H., Kuwata, K. and Miyamoto, H., 1982. Effects of Ambient Temperature on Aspects of Airborne Polycyclic Aromatic Hydrocarbons. Environ. Sci. Technol. 16: 189-194.

Yang, H.H. (1998). Characteristics of Polycyclic Aromatic Hydrocarbons and Metal Elements in the Atmospheric Environment. PhD dissertation, Department of Environmental Engineering, National Cheng-Kung University, Tainan, Taiwan.

Yang, H.H., Chiang, C.F., Lee, W.J., Hwang, K.P. and Wu, M.Y. (1999), Size Distribution and Dry Deposition of Road Dust PAHs. Environ. Int. 25: 585-597.

Yang, H.H., Hsieh, L.T. and Cheng, S.K. (2005). Determination of Atmospheric Nitrate Particulate Size Distribution and Dry Deposition Velocity for Three Distinct Areas. Chemosphere 60: 1447-1453.

Received for review, December 5, 2006

Accepted, January 21, 2007 